\title{
Bağımsız Değiş̧kenin Pareto Dağılımına Sahip Olması Durumunda Üyelik Fonksiyonunun Dayalı Parametre Tahmini
}

\author{
TÜRKAN ERBAY DALKILIÇ* \\ tedalkilic@gmail.com
}

\author{
TUĞBA KARAN** \\ tugba.karan@tuik.gov.tr
}

Özet: Basit ve çoklu doğrusal regresyon çözümlemesinde klasik metotlardan yararlanıliyorsa, modele ilişkin parametrelerin tahmini bazı varsayımlara dayanır. Doğrusal regresyon modellerinin bilinmeyen parametrelerinin tahmininde verilerin normal dağılım dişında bir dağılıma sahip olması durumu tahmin sürecinde klasik çözümlemelerin dışına çıkılmasını gerektirir. Böyle durumlarda bulanık mantı̆̆a dayalı çözümleme yöntemleri alternatif yöntemler olarak kendini göstermektedir. Bu çalışmada, bağımsız değişkenlerden herhangi birinin Pareto dağılımına sahip olması ve veri setinde aykırı gözlemlerin mevcut olması durumunda, kurulacak çoklu doğrusal regresyon modelinin bilinmeyen parametrelerini tahmin etmek için bir algoritma önerilerek, algoritmadan elde edilen tahminler literatürde yer alan mevcut yöntemlerden elde edilen tahminler ile karşılaştırılmıştır.

Anahtar kelimeler: Parametre Tahmini, Bulanık Üyelik Fonksiyonu, Pareto Dă̆ılımı.

\section{Giriş}

Regresyon çözümlemesi yöntemlerinin her biri için veri analizi oldukça önemlidir. Çünkü veri setinde yer alan değişkenlerin hangi dağılımdan geldikleri regresyon modelindeki parametre tahminleri için belirleyici rol oynamaktadır (Zadeh, 1965). Ayrıca veri setinde aykırı gözlemlerin varlığı da kullanılacak yöntemin önemini artırmaktadır. Çünkü aykırı gözlemler yapılacak parametre tahminlerini ana veri setinden uzaklaştıracak önemde olabilir. Basit ve çoklu doğrusal regresyon modellerinin bu varsayım bozulmalarından etkilenme düzeyini en aza indirgemek üzere literatürde Huber, Hampel, Andrews ve Tukey gibi güçlü (robast), model tahmin yöntemleri mevcuttur.

Pareto analizi, değişik sayıdaki önemli nedenleri daha az önemde olan nedenlerden ayırmak için kullanılan bir yöntemdir. Willfredo Pareto isimli İtalyan ekonomist Pareto Prensibi de denilen 80/20 kuralını ortaya çıkarmış ve bu kural Pareto analizi yönteminin temelini oluşturmuştur. Willfredo Pareto ilk olarak İtalya topraklarının \% 80' ine nüfusun \%20'sinin sahip olduğunu fark ederek bu prensibi kurmuştur.

Bu çalışmada, bağımsız değişkenlerden en az birinin Pareto dağılımına sahip olması durumunda, kurulacak çoklu doğrusal regresyon modelinin bilinmeyen paramet-

\footnotetext{
* Doç. Dr., Karadeniz Teknik Üniversitesi, Fen Fakültesi İstatistik ve Bilgisayar Bilimleri Bölümü.

** İstatistikçi, TÜİK İstanbul Bölge Müdürlüğü.
} 
relerini tahmin etmede normal dağılıma uymama sorunlarından mümkün olduğu kadar az etkilenen bir tahmin yöntemi önerilmiştir. Bağımsız değişkenlerden Pareto dağılımına sahip olan değişkenin modele katkısı, Pareto dağılımına uygun elde edilen üyelik fonksiyonu ile derecelendirilmiştir. Bu anlamda kullanılan yöntem güçlü (robast) yöntemler sınıfında değerlendirilebilir.

Zadeh, (1965) Bulanık yaklaşım konusundaki ilk ciddi adımı 1965 yılında yayınlanan "Bulanık Kümeler" adlı makale ile atmıştır. Zadeh bulanık mantığın matematik ve bilgisayar bilimleri alanlarındaki uyarlanabilirliği üzerinde durmuştur.

Civanlar ve Trussel (1986) "İstatistiksel veriler kullanılarak üyelik fonksiyonlarının oluşturulması" başlıklı çalışmalarında üyelik fonksiyonunun belirlenmesinin, bulanık küme teorisinin pratik uygulamalarında önemli olduğu belirtilmiş ve elemanları bilinen bir olasılık yoğunluk fonksiyonu ile belirleyici niteliklere sahip, bulanık kümelere dair üyelik fonksiyonunun belirlenmesi için bir yöntem sunmuşlardır. Çalışmada üyelik fonksiyonunun sağlaması gereken koşullar da verilmiştir.

Dombi (1990) üyelik fonksiyonları üzerine yaptığı çalışmada kullanılan farklı üyelik fonksiyonlarını tanımlamış, üyelik fonksiyonlarının kurulması için gerekli özellikler ve üyelik fonksiyonlarının matematiksel formları ile ilgili bilgi vermiştir.

Erbay Dalkılıç (2005) bağımsız değişkenlerin üstel dağılımdan gelmesi durumunda switching regresyonda bulanık sinir ağları yaklaşımı ile parametre tahmini yapmış ve mevcut tahmin yöntemlerinden elde edilen sonuçlar ile karşılaştırmıştır.

Çalışmanın uygulama kısmında önerilen yöntemin geçerliliğinin irdelenebilmesi için sayısal örneklere yer verilmiş ve ele alınan veri setleri için elde edilen sonuçlar literatürde var olan klasik yöntemlerden elde edilen sonuçlar ile karşılaştırılmıştır.

\section{1. Üyelik Fonksiyonu}

Ele alınan problemlerin yapılarına göre üyelik fonksiyonları farklılıklar gösterebilmektedir. Bununla birlikte üyelik fonksiyonlarının ortak birtakım özellikleri bulunmaktadır; üyelik fonksiyonları sürekli fonksiyonlardır ve bir [a,b] aralığını $\mu(\mathrm{x})$ fonksiyonu yardımı ile $[0,1]$ aralığına dönüştürürler. Üyelik fonksiyonunun doğrusal biçimde ya da doğrusallaşabilen bir yapıda olması büyük önem taşımaktadır. Optimal üyelik fonksiyonunun bulunabilmesi için;

$$
\text { 1. } \mathrm{E}\{\mu(\mathrm{x}) \mid \mathrm{x} \text { bir olasılık yoğunluk fonksiyonuna göre dağ } 1 \mathrm{lsın}\} \geq 0
$$

$$
\text { 2. } 0 \leq \mu(\mathrm{x}) \leq 1
$$

\section{3. $\int \mu^{2}(x) d(x)$ en küçüklenmelidir.}

biçiminde verilen koşulların sağlanması gerekmektedir. Bu koşullar altında optimal üyelik fonksiyonu;

$$
\mu(x)=\left\{\begin{array}{cc}
\lambda p(x) & \text { eğer } \lambda p(x)<1 \\
1 & \text { eğer } \lambda p(x) \geq 1
\end{array}\right.
$$


biçimindedir. Burada,

$$
\begin{array}{ll}
\mathrm{p}(\mathrm{x}) & : \text { olasılık yoğunluk fonksiyonu } \\
\lambda & : \text { sabit }
\end{array}
$$

tir (Civanlar ve Trussel, 1986). Verilen üyelik fonksiyonunda $\mathrm{p}(\mathrm{x})$, ilgilenilen dağ $1 l_{1-}$ ma ilişkin olasılık yoğunluk fonksiyonu olduğundan formu belirlidir. Ancak $\lambda$ sabiti,

$$
\begin{array}{r}
\text { P: } \min _{\mu} f(\mu)=\frac{1}{2} \int_{-\infty}^{+\infty} \mu^{2}(x) d(x) \\
G(\mu)=c-E\{\mu\}=c-\int_{-\infty}^{+\infty} \mu(x) p(x) d(x) \leq 0 \\
\mu \in \Omega=\{\mu(x) \mid 0 \leq \mu(x) \leq 1\}
\end{array}
$$

ile tanımlanan problemin çözümü ile elde edilebilir. P ile verilen problem, optimal üyelik fonksiyonu için tanımlanan koşullardan oluşturulmaktadır. $\lambda$ sabitinin elde edilmesi için, Eşitlik (2)' de P ile ifade edilen problem, Langrange yöntemi ile çözümlenebilir.

$$
L(\mu, \lambda)=\frac{1}{2} \int_{-\infty}^{+\infty} \mu^{2}(x) d(x)+\lambda\left\{c-\int_{-\infty}^{+\infty} \mu(x) p(x) d(x)\right\}
$$

biçimindedir. Burada, $\lambda \geq 0$ langrange çarpanı ve $\mathrm{c}<1$ olacak biçimde bir sabittir.

Eşitlik (1)' de verilen üyelik fonksiyonunun değerleri Eşitlik (3)' te yerine konularak $\lambda$ sabitinin değerini verebilecek fonksiyona ulaşılmaya çalışılır. Bunun için $(\lambda p(x))$ $\leq 1$ ve $(\lambda \mathrm{p}(\mathrm{x}))>1$ biçimindeki iki durum için çözümleme yapılır:

i) $\quad(\lambda \mathrm{p}(\mathrm{x})) \leq 1 \Rightarrow \mu(\mathrm{x})=\lambda \mathrm{p}(\mathrm{x})$

olur. Bu durumda,

$$
\begin{aligned}
& L=\frac{1}{2} \int_{-\infty}^{+\infty} \lambda^{2} p^{2}(x) d(x)-\lambda \int_{-\infty}^{+\infty} \lambda p^{2}(x) d(x)+\lambda c \\
& L=-\frac{1}{2} \int_{-\infty}^{+\infty} \lambda^{2} p^{2}(x) d(x)+\lambda c
\end{aligned}
$$

elde edilir. Bu fonksiyonun $\lambda$ sabitine göre türevi alındığında,

$$
\frac{\partial \mathrm{L}}{\partial \lambda}=-\lambda \int_{-\infty}^{+\infty} \mathrm{p}^{2}(\mathrm{x}) \mathrm{d}(\mathrm{x})+\mathrm{c}
$$

eşitliğine ulaşılır. 
ii) $\quad(\lambda \mathrm{p}(\mathrm{x}))>1 \Longrightarrow \mu(\mathrm{x})=1$

olur. Bu durumda,

$$
\mathrm{L}=\frac{1}{2} \int_{-\infty}^{+\infty} \mathrm{d}(\mathrm{x})-\int_{-\infty}^{+\infty} \lambda \mathrm{p}(\mathrm{x}) \mathrm{d}(\mathrm{x})+\lambda \mathrm{c}
$$

elde edilir. Bu fonksiyonun $\lambda$ sabitine göre türevi alındığında;

$$
\frac{\partial \mathrm{L}}{\partial \lambda}=0-\int_{-\infty}^{+\infty} \mathrm{p}(\mathrm{x}) \mathrm{d}(\mathrm{x})+\mathrm{c}
$$

eşitliğine ulaşıllır. İkinci aşamada elde edilen (5) eşitliği $\lambda^{\prime}$ dan bağımsız olduğu için, birinci aşamada elde edilen (4) eşitliği kullanarak $\lambda$ parametresi,

$$
\frac{\partial \mathrm{L}}{\partial \lambda}=-\lambda \int_{-\infty}^{+\infty} \mathrm{p}^{2}(\mathrm{x}) \mathrm{d}(\mathrm{x})+\mathrm{c}
$$

eşitliğinden,

$$
\lambda=\frac{c}{\int_{-\infty}^{+\infty} p^{2}(x) d(x)}
$$

biçiminde elde edilir (Klir, Yuan, 1995; Baykal, Beyan, 2004; Chen, Wang, 1999).

\section{Pareto Dağılımı için Optimal Üyelik Fonksiyonunun Belirlenmesi}

$\mathrm{Bu}$ çalışmada veri setinde yer alan değişkenlerden herhangi birinin Pareto dağılımına sahip olması ve aykırı değerlerin varlığı durumunda doğrusal regresyon modelinin parametrelerinin tahmini ile ilgilenildiğinden, Pareto dağılımına ilişkin üyelik fonksiyonu Civanlar ve Trussel (1986) tarafından önerilen bu yöntem kullanılarak aşağıdaki gibi elde edilmiştir:

Eğer X Pareto dağılımına sahip rastgele bir değişken ise olasılık yoğunluk fonksiyonu,

$$
f\left(x ; k, x_{m}\right)=k \frac{x_{m}^{k}}{x^{k+1}} x \geq x_{m}
$$

biçimindedir. Pareto dağılımı için optimal üyelik fonksiyonun elde edilmesi için öncelikle dağılıma uygun $\lambda$ parametresi belirlenmelidir. Pareto dağılımına ilişkin eşitlik ile verilen olasılık yoğunluk fonksiyonu eşitliğinde yerine konulduğunda $\lambda$ sabiti, 


$$
\begin{aligned}
& \lambda=\frac{c}{\int_{x_{m}}^{+\infty} p^{2}(x) d(x)}=\frac{c}{\int_{x_{m}}^{+\infty} k\left[\frac{x_{m} k}{x^{k+1}}\right]^{2} d(x)} \\
& \lambda=\frac{c}{k^{2} x_{m}^{2 k} \int_{x_{m}}^{+\infty} \frac{1}{x^{2(k+1)}} d(x)} \\
& \lambda=c \frac{2(k+1) x_{m}}{k^{2}}
\end{aligned}
$$

biçiminde elde edilir. Üyelik fonksiyonu, (9) eşitliği ile elde edilen $\lambda$ parametresini kullanarak,

$$
\begin{aligned}
& \mu(x)=\lambda p(x)=c \frac{2(k+1) x_{m}}{k^{2}} k \frac{x_{m}{ }^{k}}{x^{k+1}} \\
& \mu(x)=\frac{2(k+1)}{k}\left(\frac{x_{m}}{x}\right)^{k+1}
\end{aligned}
$$

biçiminde elde edilir.

\section{Uygulama}

Önerilen algoritmanın geçerliliğinin sınanması için bu bölümde ele alınan veri seti 149 gözlemden oluşmakta ve verilerin bir kısmı Tablo 1'de yer almaktadır. Veri setinde bir bağımlı ve üç bağımsız değişken bulunmaktadır. Bağımlı değişken $Y$, bağımsız değişkenler $\mathrm{X}_{1}, \mathrm{X}_{2}$, ve $\mathrm{X}_{3}$ ile ifade edilmiştir. Tablo 1 ayrıca önerilen algoritmadan ve EKK yönteminden elde edilen tahminleri ve tahminlere ilişkin hataları da içermektedir (Gamgam, Altunkaynak, 2012; Köseoğlu, Yamak, 2004).

$\mathrm{H}_{0}: \mathrm{O}_{\mathrm{i}}=\mathrm{e}_{\mathrm{i}}$ (gözlenen frekans beklenen frekanslara uygundur.)

$\mathrm{H}_{1}: \mathrm{O}_{\mathrm{i}} \neq \mathrm{e}_{\mathrm{i}}$ (gözlenen frekans beklenen frekanslara uygun değildir.)

Bağımsız değişkenlerden $\mathrm{X}_{3}$ 'e ilişkin Kolmogrov-Smirrnov (K-S) uyum iyiliği testine göre $\left(k=2,8, x_{m}=5,2\right)$ parametreleri ile Pareto dağılımına sahip olduğu hesaplanmıştır.

$$
\mathrm{K}-\mathrm{S}_{\text {Hesaplanan Değer }}=(0,0472)<\mathrm{K}-\mathrm{S}_{\text {Tablo Değeri }}=(0,1335)
$$

olduğundan $\mathrm{X}_{3}$ rasgele değişkeninin dağılımının Pareto dağılımından farkı yoktur biçiminde kurulan yokluk hipotezi, $\mathrm{H}_{0}$ kabul edilir. 
Tablo 1. Veri Setine İlişkin Tahminler ve Hatalar

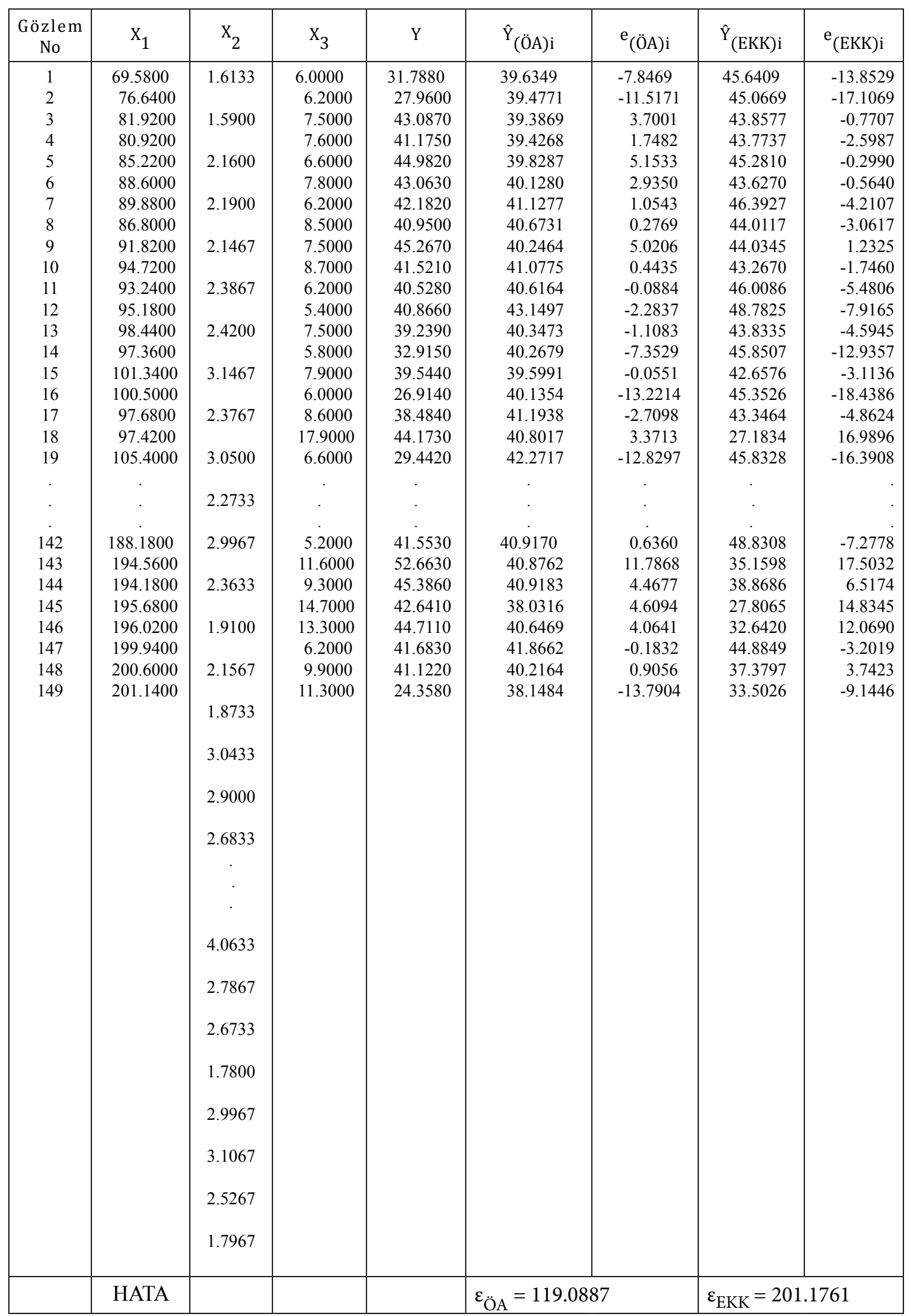


Verilere ilişkin çoklu doğrusal regresyon modelini elde etmeden önce Pareto dağglımı gösterdiği belirlenen $\mathrm{X}_{3}$ değişkenine ilişkin üyelik dereceleri,

$$
\mu\left(X_{3 i}\right)=\frac{2(k+1)}{k}\left(\frac{X_{3 m}}{X_{3 i}}\right)^{k+1}
$$

ile belirlenir, burada $\mathrm{k}=2,8$ ve $\mathrm{X}_{3 \mathrm{~m}}=5,2$ dir. Ayrıca, [0,1] aralığında değerler alabilen c sabiti 0.4 olarak belirlenmiştir. Bu sabit, üyelik fonksiyonunun olasılık yoğunluk fonksiyonuna uyumunun kontrolü ile elde edilmiştir. Önerilen algoritma için çoklu doğrusal regresyon modeline ilişkin parametre değerleri, $\mathrm{X}$ matrisinde $\mathrm{X}_{3}$ rasgele değişkeni üyelik fonksiyonundan elde edilen üyelik dereceleri ile ağırlıklandırılmış olmak üzere;

$\mathrm{B}=\left(\mathrm{X}^{\mathrm{T}} \mathrm{X}\right)^{-1} \mathrm{X}^{\mathrm{T}} \mathrm{Y}$

eşitliğinden ve MATLAB da yazılan ve önerilen algoritmanın işleyişini sağlayan program ile;

$\hat{\mathrm{Y}}_{\mathrm{ÖA}}=37.6244+0.01785 \mathrm{X}_{1}+0.9888 \mathrm{X}_{2}+100.9175 \mathrm{X}_{3}$

biçiminde elde edilmiştir. En Küçük Kareler yöntemine ilişkin model ise;

$\hat{\mathrm{Y}}_{\mathrm{EKK}}=54.4619-0.0263 \mathrm{x}_{1}+2.0167 \mathrm{x}_{2}-1.7076 \mathrm{x}_{3}$

biçimindedir.

Önerilen algoritmadan elde edilen modelin tahmin değerlerine ilişkin hata $\varepsilon_{\mathrm{ÖA}}=119.0887$, En Küçük Kareler yönteminden elde edilen modelin tahmin değerlerine ilişkin hata $\varepsilon_{\mathrm{EKK}}=201.1761$ olarak elde edilmiştir. Şekil 1-a En küçük Kareler modelinden elde edilen hata miktarlarını, Şekil 1-b önerilen algoritmadan elde edilen tahminlerin hata miktarlarını göstermektedir. Tüm modellerden elde edilen hatalar grafikleri karşılaştırmalı olarak Şekil 1-c’de yer almaktadır.

Önerilen algoritma ile elde edilen tahminlerin En Küçük Kareler yönteminden elde edilen modele ilişkin tahminlerden daha küçük hatalara sahip olduğu gözlenmiştir. 

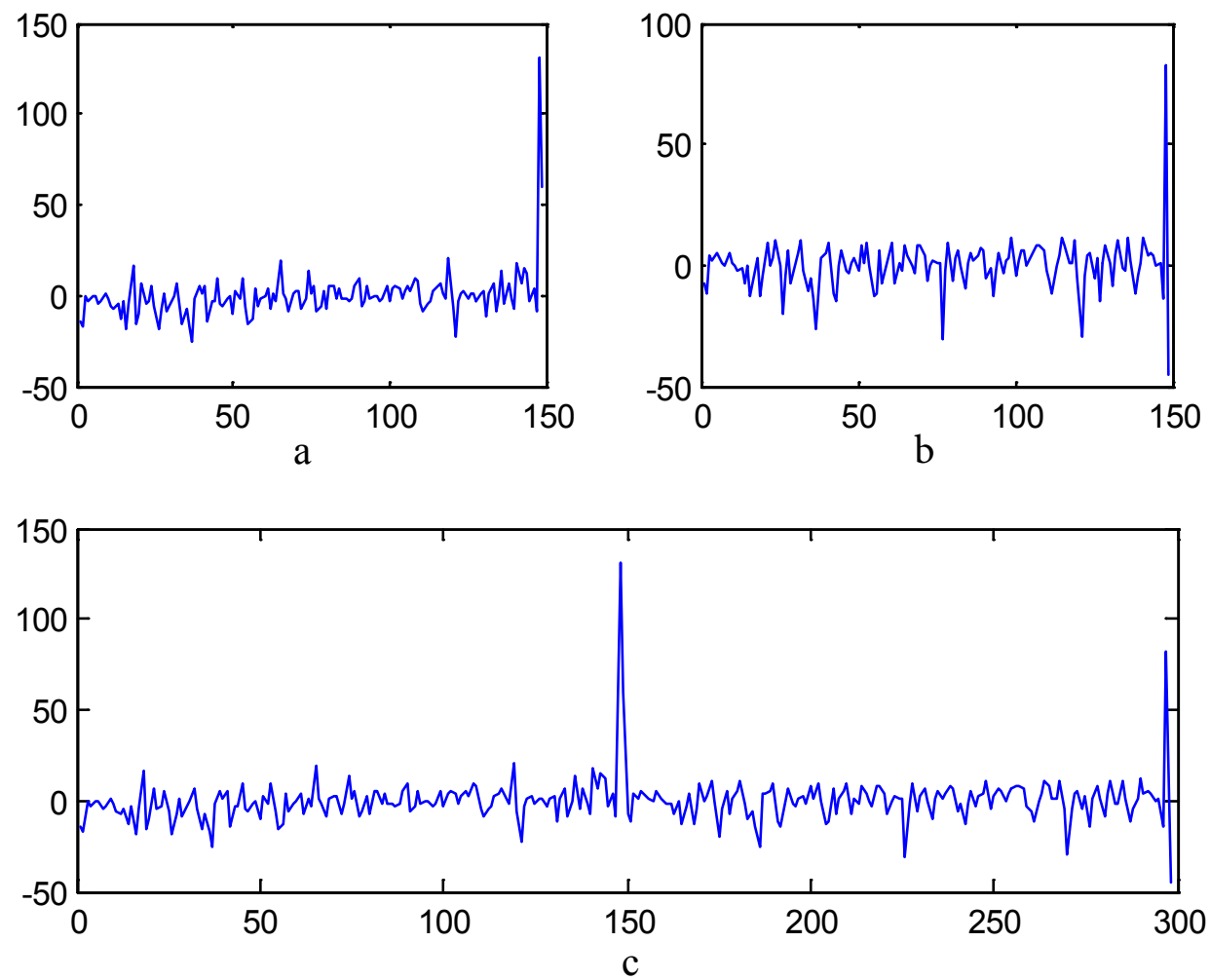

Şekil 1. Tablo 1'de yer alan veri setine ilişkin hata grafikleri

\section{Sonuç ve Öneriler}

Çoklu doğrusal regresyon analizinde kurulacak modele ilişkin bağımsız değişkenlerden herhangi biri Pareto dağılıma sahip olduğunda klasik yöntemlerin dışına çıkılması gerektiği belirtilmişti. Bu çalışmada çoklu doğrusal regresyon modeline ilişkin parametre tahmini sürecinde, Pareto dağılımı gösteren bağımsız değişkenin ağırlıklandırılmasında kullanılmak üzere, Pareto dağılımına uygun, dağılımın olasılık yoğunluk fonksiyonuna dayalı üyelik fonksiyonu elde edilmiştir. Çoklu doğrusal regresyon modelinin bilinmeyen parametreleri önerilen yöntem ve literatürde yer alan En Küçük Kareler yöntemi ile tahmin edilerek, belirlenerek modellerin performansları verdikleri tahmin değerleri ve bu değerlere ilişkin hata miktarları ile karşılaştırılmıştır. Elde edilen tahminlere ilişkin hata miktarlarının düşük olması, önerilen yöntemin, karşılaşılacak çoklu doğrusal regresyon modeli kurma problemlerinde alternatif olarak kullanılabilir olduğunu göstermektedir. Bağımsız değişkenlerden herhangi birinin Pareto dağılımı dışında başka dağılımlara sahip olmaları durumu irdelenerek bu durumlara ilişkin yöntemler geliştirilebilir. 


\section{Kaynakça}

Baykal, Nazife ve Timur Beyan. Bulanık Mantık İlke ve Temelleri. Ankara: Bıçaklar Kitabevi, 2004.

Chen, M. S. ve Wang, S. W. "Fuzzy Clustering Analaysis for Optimizing Fuzzy Membership Functions”. Fuzzy Sets and Systems 103. (1999): 239-254.

Civanlar, M. R. ve Trussell, H. J. “Tructing Membership Functions Using Statistical Data”. Fuzzy Sets and Systems 18. (1986): 1-13.

Dombi, J. "Membership Functions As An Evalution”. Fuzzy Sets and Systems 35. (1990): 1-21.

Erbay, Dalkılıç, Türkan. “Switching Regresyon'da Bulanık Sinir Ağları Yaklaşımı ile Parametre Tahmini”. Doktora Tezi, Ankara Üniversitesi, Fen Bilimleri Enstitüsü, 2005.

Gamgam, Hamza ve Bülent Altunkaynak. SPSS Uygulamalı Parametrik Olmayan Yöntemler. Ankara: Seçkin Yayıncılık, 2012.

Klir, G. J. ve Yuan, B. Fuzzy Sets and Fuzzy Logic, USA: Prentice-Hall, 1995.

Köseoğlu, Mustafa ve Rahmi Yamak. Uygulamalı İstatistik ve Ekonometri. Trabzon: Celepler Matbaacilık, 2004.

Zadeh, L. A. “Fuzzy Sets”. Informationand Control 8. (1965): 338-353. 


\section{Parameter Estimation Based on Membership Function When an Independent Variable Has Pareto Distribution}

TÜRKAN ERBAY DALKILIÇ / TUĞBA KARAN

Abstract: If classical methods are being employed in simple and multiple linear regression analysis, estimation of parameters related to the model is based on some assumptions. If the data have any distribution other than normal distribution in estimation of unknown parameters of linear regression models, the analysis has to go beyond classical analysis. In such cases analysis methods based on fuzzy logic manifest themselves as alternative ways. In this paper, an algorithm has been proposed in order to be able to estimate the unknown parameters of multiple linear regression model in the case that any independent variable has a Pareto distribution and incompatible observations exist in data set and estimations obtained from this algorithm have been compared with estimations obtained from the methods existing in the literature.

Keywords: Parameter Estimation, Fuzzy Membership Function, Pareto Distribution. 